\title{
A voz como estratégia narrativa no cinema experimental: sintonias entre a teoria feminista do cinema e as vanguardas artísticas
}

Gustavo Soranz*

Resumo: Apontamos as sintonias entre a teoria feminista do cinema e certo cinema experimental produzido por mulheres, cujas práticas desafiam as formas mais sexistas e fetichistas do modelo hegemônico. Nesta seara encontramos o cinema de Trinh T. Minh-ha, que explora estratégias expressivas que utilizam o som como recurso essencial de uma prática experimental que nos permite ver o encontro entre a teoria e a prática.

Palavras-chave: teoria do cinema; vanguardas artísticas; cinema experimental; documentário.

Resumen: Apuntamos las sintonías entre la teoría feminista del cine y cierto cine experimental producido por mujeres, cuyas prácticas desafían las formas más sexistas y fetichistas del modelo hegemónico. En esta secuela encontramos el cine de Trinh T. Minh-ha que explora estrategias expresivas que utilizan el sonido como recurso esencial de una práctica experimental que nos permite ver el encuentro entre la teoría y la práctica.

Palabras clave: teoría del cine; vanguardias artísticas; cine experimental; documental.

\begin{abstract}
I point out the syntonies between the feminist theory of cinema and certain experimental cinema produced by women, whose practices defy the sexist and fetishist forms of hegemonic model. With this approach one may find Trinh T. Minh-ha's cinema that exploits expressive strategies using sound as an essential resource of an experimental practice that allows the encounter between practice and theory.

Keywords: cinema theory; artistic vanguard; experimental cinema; documentary.
\end{abstract}

Résumé : Nous rappelons les liens de syntonie qui unissent la théorie féministe du cinéma et certains cinémas expérimentaux produits par les femmes, dont les pratiques défient les formes plus sexistes et fétichistes du modèle hégémonique. Dans ce domaine, nous trouvons le cinéma de Trinh T. Minh-ha qui explore des stratégies expressives qui utilisent le son comme une ressource essentielle d'une pratique expérimentale qui nous permet de voir la rencontre entre la théorie et la pratique.

Mots-clés : theorie du cinéma ; avant-gardes artistiques ; cinéma expérimental ; documentaire.

\footnotetext{
* Centro Universitário Fametro, Faculdade de Ciências Humanas e Sociais, Curso de Jornalismo. 69085-288, Manaus-AM, Brasil. E-mail: soranz@yahoo.com

Submissão do artigo: 17 de dezembro de 2017. Notificação de aceitação: 29 de janeiro de 2018.
} 
O cinema sempre foi um domínio majoritariamente masculino em suas posições de decisão e de poder. A presença de mulheres que abordaram temas importantes ao universo feminino, sintonizadas com disputas conduzidas no campo social pela igualdade de direitos ou em favor de conquistas políticas sempre foi tímida, especialmente em relação ao cinema narrativo e ao esquema industrial de produção. Entretanto, com o passar das décadas, e em sintonia com as disputas e avanços do movimento feminista, algumas cineastas exemplares foram responsáveis por trabalhos importantes que inseriram no campo da produção artística as questões relevantes para as mulheres, de modo que contribuíram em problematizar a produção artística de um ponto de vista feminino. O caminho para que algumas mulheres pudessem assumir posições de comando na produção cinematográfica, especialmente na função de diretoras, demandou tempo e avanços dentro da indústria do cinema. Geralmente ocupando lugares secundários nas produções, em posições consideradas mais adequadas ao que seria o papel da mulher (são conhecidos os casos das mulheres montadoras, cuja função evocava uma associação com o ato de costurar típico de uma ideia préconcebida de certo universo doméstico feminino) ou em posições cuja visibilidade estava fortemente marcada por papéis sociais já legitimados pela ideologia dominante (como o lugar fetichizado das atrizes no star system), algumas superaram os desafios impostos pelas questões sexistas e passaram para postos de comando prioritariamente reservados para os homens.

Não nos deteremos em detalhes relacionados à presença feminina na produção cinematográfica industrial. Neste artigo nos interessam cineastas com presença no universo das vanguardas artísticas, frequentemente atuantes em diferentes frentes de modo interdisciplinar. Em particular, nossa atenção está voltada para cineastas cuja atuação denota aproximação entre a teoria crítica e a política cultural. São realizadoras cuja atuação evidencia um cenário de produção que se fortaleceu fora dos esquemas industriais ou comerciais de produção, propriciado por inovações tecnológicas que baratearam os custos da produção e permitiram a consolidação de um modelo de cinema mais livre e menos normatizado por convenções hegemônicas, estas últimas geralmente associadas a poderes econômicos e políticos dominados pelo universo masculino.

Apesar de historicamente serem poucas as mulheres em posições de protagonismo no cinema, conforme assinalamos acima, há nomes importantes que fizeram parte de sua evolução como forma expressiva. Alguns nomes poderiam ser lembrados, como o de Germaine Dulac, por exemplo, que transitou entre filmes narrativos e experimentos surrealistas, contribuindo para explorar os meios cinemáticos em sua especificidade, dirigindo diversos filmes entre as 
A voz como estratégia narrativa no cinema experimental: sintonias entre a teoria feminista do cinema e as vanguardas artísticas

décadas de 1910 e 1930. Todavia, consideramos que o nome mais importante a destacar, e que responde aos fatores de experimentação formal que apontamos acima, é o de Maya Deren, cineasta norte-americana de origem ucraniana, que desenvolveu profícuo trabalho de vanguarda nas artes nas décadas de 1940 e 1950, com especial interesse pelas artes performáticas, pela poesia e pelo cinema. Sua atuação estendeu-se ao diálogo com o campo da antropologia, quando, em 1947, ela foi contemplada com uma bolsa da Guggenheim Foundation Fellowship que a permitiu realizar três visitas ao Haiti entre 1947 e 1954. De tais visitas resultaram a publicação de um livro, gravações de áudio e a realização de filmagens da pesquisa sobre os rituais da tradição religiosa haitiana do vodu que deram origem ao filme Divine Horsemen: the living gods of Haiti, de 1953.

Maya Deren tinha uma formação artística e intelectual multidisciplinar. Originalmente atuante no campo da dança, chega ao cinema pelo caminho da experimentação das vanguardas artísticas. Foi defensora de um cinema que deveria primar pela busca de uma forma expressiva original, explorando as potencialidades dos recursos da imagem e do som em detrimento dos modelos narrativos tributários do teatro e da literatura. Em seu famoso ensaio Cinema: o uso criativo da realidade, publicado originalmente em 1960, ela escreveu que

Se o cinema se destina a ocupar seu lugar entre as formas artísticas plenamente desenvolvidas, deve deixar de meramente registrar realidades que não devem nada de sua existência ao instrumento fílmico. Pelo contrário, deve criar uma experiência total, oriunda da própria natureza do instrumento a ponto de ser inseparável de seus próprios recursos. Deve renunciar às disciplinas narrativas que emprestou da literatura e sua tímida imitação da lógica causal dos enredos narrativos, uma forma que floresceu como celebração do conceito terreno e paulatino de tempo, espaço e relação que foi parte do materialismo primitivo do século XIX. Pelo contrário, deve desenvolver o vocabulário de imagens fílmicas e amadurecer a sintaxe de técnicas fílmicas que as relaciona. Deve determinar as disciplinas inerentes ao meio, descobrir seus próprios modos estruturais, explorar os novos campos e dimensões acessíveis a ele e assim enriquecer artisticamente nossa cultura, como a ciência o fez em seu próprio domínio. (Deren, 2012: 149).

De par com as questões especificamente cinematográficas, podemos notar nesse texto preocupações típicas das vanguardas artísticas da primeira metade do século XX, especialmente no que tange a experimentação em relação a forma e ao conteúdo. Além disso, a atuação de Maya Deren no campo das artes já anunciava preocupações associadas ao feminismo, com destaque para o protagonismo da mulher em seus trabalhos, que contaram com a força de sua 
presença em tela em parte de sua produção fílmica. Contudo, em seus escritos, os temas feministas ainda não estavam contemplados diretamente.

A teoria feminista chega ao cinema na década de 1970, reverberando os avanços da chamada segunda onda feminista, que desde o fim da Segunda Guerra Mundial lograva progressos no campo das disputas políticas e pela liberação das mulheres, com especial relevância a partir da década de 1960, quando as demandas do movimento se diversificam em termos de posicionamentos e interesses, acompanhando as demandas sociais e as agitações geopolíticas ao redor do mundo. Na teoria do cinema o impacto do feminismo segue essa diversificação de interesses, além de refletir também a diversidade institucional do cinema. Inicialmente podemos identificar trabalhos dedicados a questionar o sexismo dentro dessa indústria, produções que faziam propaganda de questões feministas, debates sobre política cultural e análises do fetichismo na representação cultural através do filme.

A inglesa Laura Mulvey é uma das principais vozes na teoria feminista do cinema, com trabalhos incontornáveis em se tratando dessa temática. Seu texto Prazer visual e cinema narrativo, escrito em 1973 e publicado na revista Screen em 1975, continua sendo uma referência fundamental para as questões desse interesse, mesmo décadas após sua primeira publicação. Além de vasta produção de interesse na teoria de cinema, Mulvey também produziu alguns filmes ao lado de Peter Wollen, com destaque para Riddles of the Sphynx, de 1977, considerado um dos mais importantes filmes experimentais ingleses dessa década. $\mathrm{O}$ trabalho explora questões da representação feminina, o lugar da maternidade dentro da sociedade patriarcal e relações entre mãe e filha. Cabe notar que Mulvey e Wollen são dois proeminentes teóricos do cinema, cujo trabalho intelectual emerge nesse período em que a própria teoria do cinema ainda avançava nos terrenos da investigação acadêmica e buscava consolidar suas bases e referências. Para Mulvey ${ }^{1}$

A colisão entre o feminismo e o cinema é parte de um encontro explosivo maior entre o feminismo e a cultura patriarcal. Desde muito cedo, os movimentos das mulheres chamaram a atenção para o significado político da cultura: a ausência das mulheres da criação da arte dominante e da literatura como um aspecto integral da opressão. A partir deste insight, outros debates sobre política e estética adquiriram nova vida. Foi o feminismo (não exclusivamente, mas em boa medida) que deu uma nova urgência à política da cultura e focou nas conexões entre opressão e comando da linguagem. Amplamente excluídas das tradições criativas, submetidas à ideologia patriarcal dentro da literatura, artes populares e representações visuais, as mulheres tiveram que formular uma oposição ao sexismo cultural e descobrir meios de expressão

1. As traduções dos textos originais são de nossa autoria. 
A voz como estratégia narrativa no cinema experimental: sintonias entre a teoria feminista do cinema e as vanguardas artísticas

que quebrassem com uma arte que tinha dependido para sua existência de um conceito exclusivamente masculino de criatividade. ${ }^{2}$ (1989: 111).

Essa afirmação de Mulvey sintetiza alguns avanços da crítica feminista do cinema, que tinha um interesse inicial em delinear uma tradição do cinema feito por mulheres, apontando que a exclusão destas das posições de comando nessa área tem relação proporcional com a exploração da mulher como objeto sexual. Para esse fim, seria necessário evidenciar tais filmes para tentar apontar elementos estilísticos de modo a reconhecer neles uma estética feminina coerente.

Entretanto, tais suposições iniciais mostraram-se inadequadas para a crítica feminista do cinema que se esboçava, pois demonstraram que precisavam ganhar maior densidade para lidar com as questões que o cinema exigia enquanto meio simbólico sofisticado que é. Podemos verificar essa necessidade nesta declaração de Laura Mulvey:

A experiência da opressão, o reconhecimento da exploração da mulher na imagem, poderia atuar como um elemento unificador para as mulheres diretoras, apesar de suas origens serem diferentes. Uma análise cuidadosa mostraria como as disputas associadas com ser mulher sob dominação masculina encontravam uma expressão que unificava através de diversidades de todos os tipos. Certamente, os filmes feitos por mulheres foram predominantemente sobre mulheres, seja por escolha ou por outro aspecto ou marginalização. Mas começou a parecer crescentemente duvidoso que uma tradição unificada pudesse ser traçada, exceto em um nível superficial de mulheres como conteúdo. ${ }^{3}$ (1989: 114).

A crítica feminista do cinema avançaria então no sentido de superar essas estratégias iniciais de forma a desenvolver "cuidadosas e detalhadas análises da linguagem e códigos usados por uma diretora sozinha em um mundo de outra forma exclusivamente masculino. Tal trabalho se tornou um avanço cru-

2. No original: The collision between feminism and film is part of a wider explosive meeting between feminism and patriarchal culture. From early on, the Women's Movement called attention to the political significance of culture: to women's absence from the creation of dominant art and literature as an integral aspect of oppression. Out of this insight, other debates on politics and aesthetics acquired new life. It was (not exclusively, but to an important extent) feminism that gave a new urgency to the politics of culture and focused attention on connections between oppression and command of language. Largely excluded from creative traditions, subjected to patriarchal ideology within literature, popular arts and visual representation, women had to formulate an opposition to cultural sexism and discover a means of expression that broke with an art that had depended, for its existence, on an exclusively masculine concept of creativity.

3. No original: The experience of oppression, awareness of women's exploitation in image, would act as a unifying element for women directors, however different their origins. Careful analysis would show how the struggles associated with being female under male domination found an expression that unified across diversity of all kinds. Certainly, the films made by women were predominantly about women, whether through choice or as another aspect or marginalization. But it began to look increasingly doubtful whether a unified tradition could be traced, except on the superficial level of women as content. 
cial na crítica feminista do cinema. ${ }^{4 "}$ (Mulvey, 1989: 115) Em resumo, não bastava que diretoras mulheres substituissem os personagens masculinos por personagens femininas, ou que deslocassem as personagens femininas para outras posições dentro da narrativa que não fossem aquelas identificadas com as posições subjugadas ao modelo masculino do poder patriarcal. Para que a crítica feminista do cinema avançasse em direção ao escopo de uma teoria feminista do cinema, a questão da linguagem cinematográfica deveria entrar no foco da reflexão e ser objeto de crítica, "sondando o deslocamento entre a forma cinematográfica e o material representado, e investigando vários meios de abrir o espaço fechado entre a tela e espectador. ${ }^{5 "}$ (Mulvey, 1989: 119).

Desta constatação surge o quadro teórico que vai sustentar a consolidação de uma teoria feminista do cinema, assentada sobre os pilares da investigação do signo e do inconsciente na representação, a partir de contribuições da semiologia e da psicanálise. Somado a isso, o interesse em desvendar o aparato cinematográfico é marcado fortemente pela contribuição de Louis Althusser e sua definição de ideologia, identificando-a como a representação imaginária de uma relação entre sujeito e impressão de realidade.

Porém, a questão feminista no cinema deveria ir além do campo da investigação e da teoria e deveria ser refletida no campo da produção cinematográfica propriamente dita. Quais seriam as prerrogativas da prática de um cinema produzido por mulheres que estivesse em sintonia com as questões políticas que o movimento feminista conduzia no campo das disputas sociais?

Para Claire Johnston - outra autora fundamental para delinear as bases do que viria se consolidar como uma teoria feminista do cinema - o cinema feminista deveria propor um cinema engajado no campo da estética, que utilizasse crítica e conscientemente a forma do filme e explorasse outros modos de articulação entre os diversos elementos que compõem sua linguagem. Em seu texto Women's cinema as counter-cinema, publicado inicialmente em 1973, Johnston toca diretamente na questão da forma fílmica como reflexo de uma ideologia.

Claramente, se aceitarmos que o cinema envolve a produção de signos, a ideia de não intervenção é pura mistificação. $\mathrm{O}$ signo é sempre um produto. O que a câmera de fato captura é o mundo 'natural' da ideologia dominante. O cinema das mulheres não pode permitir tal idealismo; a 'verdade' da nossa opressão não pode ser 'capturada' em celulóide com a 'inocência' da câmera: ela tem que ser construída/manufaturada. Novos significados tem que ser

4. No original: careful, detailed analysis of the language and codes used by a woman director alone in an otherwise exclusively male world.

5. No original: dislocation between cinematic form and represented material, and investigating various means of splitting open the closed space between screen and spectator. 
A voz como estratégia narrativa no cinema experimental: sintonias entre a teoria feminista do cinema e as vanguardas artísticas

criados perturbando a estrutura do cinema burguês masculino no interior do texto do filme. ${ }^{6}$ (1976: 214).

Os argumentos de Johnston nos levam a observar a experimentação formal no cinema como uma necessidade resultante de disputas ideológicas que marcaram o período histórico no qual a teoria feminista do cinema surgiu. As contendas da arena política apontavam para o desenvolvimento de uma consciência crítica em relação à forma fílmica, uma vez que no cinema hegemônico esta se configurava como resultado de mentalidades forjadas pelo pensamento "burguês masculino". Assim, para fazer frente a esse domínio, eram necessárias novas estratégias formais por parte das diretoras mulheres quanto ao dispositivo cinematográfico e seus efeitos na audiência.

Apesar de a maioria dos textos da teoria feminista do cinema se debruçar sobre o cinema narrativo, essa questão da experimentação reverbera no campo das vanguardas artísticas e do cinema experimental, algo que Laura Mulvey especificamente tratou no seu texto Film, feminism and avant-garde (1989), que estamos utilizando como base aqui em nossa exposição neste artigo. Nesse texto, Mulvey tece considerações sobre a relação da semiologia com as vanguardas artísticas que nos parecem importantes para pensar a aproximação entre a teoria feminista e o cinema experimental.

Partindo de Julia Kristeva e seu trabalho em relação à poética modernista, onde a filósofa búlgaro-francesa ligou a crise que produziu o modernismo com o 'feminino', Mulvey expõe como a semiótica coloca a questão da linguagem em primeiro plano, enfatizando a importância crucial do significante e a natureza dual do signo. Para Mulvey, Kristeva

vê a feminilidade como reprimida na ordem patriarcal e como mantendo uma relação problemática para com esta. A tradição é transgredida pela erupção de excessos linguísticos, envolvendo prazer e 'o feminino' diretamente oposto à linguagem lógica e repressão endêmica do patriarcado. Um problema permanece: nesses termos, a mulher apenas atua em relação ao que estava sendo reprimido, e é a relação poética masculina à feminilidade que entra em erupção no seu uso da linguagem poética. O próximo passo deveria, de um ponto de vista feminista, se mover para além da mulher que não fala, um significante do 'outro' do patriarcado, para um ponto onde mulheres possam falar por si mesmas, além da definição de 'feminilidade' especificada pelo patriarcado, para uma linguagem poética feita também pelas mulheres e seu discernimento. Mas o ponto importante de Kristeva é este: a trangressão é obtida pela própria linguagem. A ruptura com o passado deve atuar atra-

6. No original: Clearly, if we accept that cinema involves the production of signs, the idea of non-intervention is pure mystification. The sign is always a product. What the camera in fact grasps is the "natural" world of dominant ideology. Women's cinema cannot afford such idealism; the "truth" of our oppression cannot be "captured" on celluloid with "innocence" of the camera: it has to be constructed/manufactured. New meanings have to be created by disrupting the fabric of the male bourgeois cinema within the text of the film. 
vés dos meios que elaboram o sentido, subvertendo suas normas e recusando sua totalidade imperturbável. Aqui, por extensão, a importância do cinema independente para o feminismo aparece plenamente: é fora das restrições do cinema comercial, em debate com a linguagem, no contracinema, que a experimentação feminista pode ocupar o seu lugar. ${ }^{7}$ (1989: 121-122).

Esse destaque para a necessidade de um cinema feminista que esteja identificado com a experimentação formal é algo que aproxima esses argumentos das demandas do campo das vanguardas artísticas e particularmente do cinema experimental, como podemos notar com a argumentação de Mulvey quando esta destaca a importância do cinema independente nesse cenário. É também a pedra de toque que leva Johnston a formular a sua argumentação em relação ao que seria aquilo que ela propõe como um contracinema. Nas palavras desta, "qualquer estratégia revolucionária deve desafiar a representação da realidade; não é suficiente discutir a opressão às mulheres dentro do texto do filme; a linguagem do cinema/representação da realidade deve também ser interrogada, para que uma quebra entre ideologia e texto seja efetuada. ${ }^{8 "}$ (Johnston, 1976: 215).

Outra autora fundamental para a consolidação da teoria feminista do cinema e que coloca a questão da forma - mais precisamente das estratégias de mise en scène - em primeiro plano para discutir o cinema feminista é Mary Ann Doane, em cujo trabalho a questão do corpo feminino aparece com importante centralidade. No texto Woman's Stake: filming the female body, publicado em 1981, a autora se dedica a pensar como as estratégias de filmagem do corpo feminino deveriam ser problematizadas sob a luz dos avanços na teoria feminista do cinema, ou seja, como o feminismo deveria nortear o cinema das mulheres para além da oposição entre um essencialismo que marcou as reflexões iniciais, dominado pela questão das denúncias do sexismo no cinema,

7. No original: She sees femininity as the repressed in the patriarchal order and as standing in a problematic relation to it. Tradition is transgressed by an eruption of linguistic excess, involving pleasure and 'the feminine' directly opposed to the logical language and repression endemic to patriarchy. A problem remains: woman, in these terms, only stands for what has been repressed, and it is the male poet's relation to femininity that erupts in his use of poetic language. The next step would, from a feminist point of view, have to move beyond woman unspeaking, a signifier of the 'other' of patriarchy, to a point where women can speak themselves, beyond a definition of 'femininity' assigned by patriarchy, to a poetic language made also by women and their understanding. But Kristeva's important point is this: transgression is played out through language itself. The break with the past has to work through the means of meaning making itself, subverting its norms and refusing its otherwise imperturbable totality. Here, by extension, the importance of the independent filmmaking sector for feminism appears fully: it is outside the constraints of commercial cinema, in debate with the language of counter-cinema, that feminist experimentation can take place.

8. No original: Any revolutionary strategy must challenge the depiction of reality; it is not enough to discuss the oppression of women within the text of the film; the language of the cinema/the depiction of reality must also be interrogated, so that a break between ideology and text is effected. 
A voz como estratégia narrativa no cinema experimental: sintonias entre a teoria feminista do cinema e as vanguardas artísticas

e um antiessencialismo, que buscaria um cinema de oposição a esse modelo hegemônico. Para fugir dessa dualidade, a teoria feminista do cinema deveria arriscar-se a definir ou construir uma especificidade feminina, que pudesse providenciar uma representação simbólica autônoma da mulher no cinema. Para Doane,

Está claro, a partir das explorações anteriores das elaborações teóricas do corpo feminino, que a delimitação não está simplesmente ligada a uma imagem isolada do corpo. A tentativa de 'apoiar-se' no corpo de modo a formular a relação diferente da mulher em relação à fala, à linguagem, esclarece o fato de que o que está em jogo é, mais do que isso, a sintaxe que constitui o corpo feminino como um termo. Os mais interessantes e produtivos filmes recentes que lidam com a problemática feminista são precisamente aqueles que elaboram uma nova sintaxe e, desse modo, 'falando' sobre o corpo feminino de modo diferente, até mesmo de modo hesitante ou desarticulado da perspectiva da sintaxe clássica. ${ }^{9}$ (1981: 33).

Esta declaração de Doane nos remete diretamente para o cinema da vietnamita Trinh T. Minh-ha, cujos filmes podem ser pensados como exemplos centrais do que pode ser um cinema feminista enquanto forma e sintaxe e não apenas enquanto tema. Vejamos o caso do seu primeiro filme, Reassemblage (1982), onde o modo de filmar o corpo feminino é marcado pelo uso de estratégias atípicas na seara à qual o filme aparentemente pertence, qual seja, a do filme etnográfico. A cineasta optou por uma série de enquadramentos parciais, de corpos fragmentados e deslocados em quadro, detalhes de seios e movimentos de câmera hesitantes, articulados em uma montagem marcada por jump cuts. A narração em voz over, por sua vez, estabelece uma série de paralelos com situações que não estão ilustradas na imagem, mas que remetem a questões do encontro intercultural, problemas da etnologia, da descrição da alteridade e questões de gênero.

\section{$O$ cinema independente de vanguarda}

Desde o final da década de 1960 surgiram cineastas que colocaram a questão da representação da mulher em sintonia com uma forma fílmica vanguardista em termos de utilização dos recursos da imagem e do som. Assim fazendo, exploram as articulações da montagem e da experimentação na narrativa como forma de elaborar estéticas inovadoras, particularmente informadas

9. No original: it is clear from the preceding exploration of the theoretical elaboration of the female body that the stake does not simply concern an isolated image of the body. The attempt to "lean"on the body in order to formulate the woman's different relation to speech, to language, clarifies the fact that what is at stake is, rather, the syntax which constitutes the female body as a term. The most interesting and productive recent films dealing with the feminist problematic are precisely those which elaborate a new syntax, thus "speaking" the female body differently, even haltingly or inarticulately from the perspective of a classical syntax. 
e engajadas em debates das questões de gênero, não raro narrados sob um ponto de vista assumidamente em primeira pessoa.

Antes de avançarmos cabe aqui lembrar que, no contexto norte-americano, este cenário de produção de cinema independente foi marcado pela existência de um importante grupo de cineastas experimentais na cidade de Nova Iorque, que articularam diversas iniciativas em torno do cinema experimental underground. Uma figura central neste cenário foi a do cineasta Jonas Mekas, que, ao lado de outros entusiastas do cinema de vanguarda, fundou, no final da década de 1950, a revista Film Culture, seguida da organização da filmmakers cooperative, que seria a origem da Anthology Film Archives, dedicada a preservar a memória do cinema de vanguarda. Essa agitação cultural resultou no movimento conhecido como The new american cinema, modelo de cinema experimental, cooperativo, autofinanciado, do qual fizeram parte cineastas como Stan Brakhage e Shirley Clarke.

Apesar de não abordar diretamente temas feministas em seus filmes, o caso de Shirley Clarke nos interessa por sua atuação fundamental na consolidação de um modelo de cinema independente nos Estados Unidos. Sua produção é marcada inicialmente por filmes experimentais formalistas, como Bridgesgo-round (1958), que mostra uma sequência de sobreposições de imagens de paisagens da cidade de Nova Yorke e caminhos traçados por pontes e viadutos, com manipulação nas cores e embaladas por uma trilha de Jazz e efeitos sonoros. Ela também produziu filmes narrativos, que abordaram temas como questões de identidade e raça. Um exemplo dessa vertente é The cool world (1964), que narra de forma realista as dificuldades em ser um jovem afro-americano crescendo no ambiente urbano das grandes cidades. A cineasta ganhou um Oscar pelo documentário Robert Frost: A Lover's Quarrel With the World (1963) e teve filmes que circularam por importantes festivais como o Festival Internacional de Veneza.

Retornando a exemplos de cineastas que têm relação mais direta com as questões feministas no cenário norte-americano, podemos citar o caso de $\mathrm{Su}$ Friedrich, cujos filmes transitam entre estratégias do cinema narrativo, do documentário e do experimental, com trabalhos que refletem sobre sua vida pessoal e abordam temas relacionados ao universo feminino desde uma perspectiva homossexual, mantendo uma produção regular desde o final da década de 1970 até os dias atuais. Podemos citar entre seus trabalhos mais importantes The Ties that Bind (1985), um documentário sobre sua mãe, que emigrou da Alemanha para os Estados Unidos, tendo crescido sob o regime nazista e os horrores da guerra; Sink or Swin (1990), um filme sobre questões da sua infância que moldaram o modo de ver as relações familiares, a paternidade e as 
A voz como estratégia narrativa no cinema experimental: sintonias entre a teoria feminista do cinema e as vanguardas artísticas

relações de trabalho e lazer, a partir das memórias e eventos relacionados a um pai ausente e a conformação de seu lado afetivo; Hide and seek (1996), um filme sobre a homossexualidade na adolescência vivida na década de 1960, elaborado a partir da utilização de estratégias ficcionais, articulação de material de arquivo - filmes científicos e educacionais - e lembranças pessoais.

No cenário europeu, por sua vez, temos o caso seminal da cineasta francesa Agnès Varda, que tem vasta e importantíssima produção, desde o final dos anos 1950. Seus filmes iniciais são associados à Novelle Vague, passando para uma produção extensa com trânsito frequente entre o cinema narrativo e o documentário, com diversos exemplos de filmes inovadores na maneira como relacionam a esfera privada com a esfera pública em estratégias ensaísticas que problematizam o documentário de um ponto de vista da experiência pessoal da cineasta. Outro nome europeu importante de ser lembrado é o da cineasta belga Chantal Akerman, que também tem filmes importantes, tanto no campo do cinema narrativo como no campo do documentário. Nesse segundo caso, com filmes mais afeitos a discutir as temáticas feministas.

Nos filmes de Varda e Akerman ancorados no campo do documentário, uma das estatégias centrais na elaboração do discurso é a utilização da voz como recurso narrativo pleno de potencial expressivo. Vários filmes dirigidos pela cineasta francesa utilizam um modo poético e pessoal de locução em voz over, algo ampliado em seus últimos documentários, como é o caso de Les glaneurs et la glaneuse (2000), onde a diretora assume uma visão em primeira pessoa para refletir sobre o ato de catar ou recolher (batatas, imagens), imbricando a experiência pessoal com a experiência pública. Entre outros casos de interesse, Chantal Akerman, por sua vez, dirigiu o filme News from home (1977), no qual utilizou a locução em voz over de modo central para realizar um filme intimista rememorando cartas trocadas com sua mãe. Ao fazer isso, estabelece relações entre a experiência privada e o espaço público de modo bastante poético e original, construindo, através do cinema, uma ponte entre Nova Iorque e Bruxelas.

\section{A voz como estratégia narrativa}

Como vimos anteriormente, uma das principais contribuições da teoria feminista do cinema foi a problematização do aparato cinematográfico como uma instância relacionada à dimensão ideológica. A partir dessa concepção, teóricas ligadas a esse campo de estudos dedicaram-se a investigar como o cinema utiliza os seus recursos técnicos de modo a articular sentidos e afetar a percepção do espectador quanto aos tópicos abordados, reverberando a concepção de que enquanto teoria cinematográfica, os estudos feministas deve- 
riam refletir sobre os aspectos mais sofisticados da linguagem cinematográfica. Nessa reflexão acerca da forma do filme a partir da perspectiva aqui delineada, os aspectos ligados ao uso da voz no cinema ganharam dimensão importante.

No texto "A voz no cinema: a articulação de corpo e espaço", publicado inicialmente em 1980, Mary Ann Doane coloca a análise da voz no centro do interesse de sua investigação, oferecendo uma contribuição importante em relação às preocupações emergentes relacionadas ao aparato cinematográfico e enfatizando como as estratégias formais e estéticas deveriam ser objeto de ampla e profunda reflexão intelectual. Nesse texto ela relaciona quatro aspectos que considera fundamentais para a reflexão sobre a voz no cinema: a) a sincronização entre som e imagem, b) a diferenciação entre voz off e voz over, c) o prazer da audição e d) a política da audição.

Para Doane (1983), o cinema narrativo hegemônico recorre à sincronização entre som e imagem como um recurso fundamental para suas estratégias narrativas que buscam a transparência e a impressão de realidade, que atuam diretamente para a identificação da audiência com o realismo cinematográfico. Nesta relação entre voz e corpo, as possibilidades criativas desse encontro ficam sacrificadas e o som adquire mero caráter de reprodução, na qual a voz necessita estar ancorada em um determinado corpo e este em um determinado espaço, para reforçar o efeito mimético de um realismo cinematográfico.

Em nome de uma análise acurada, a autora enfatiza a importância da conceituação precisa em relação aos usos da voz no cinema, diferenciando as categorias de voz off e voz over. O primeiro termo, voz off, está relacionado à diegese e tem uma dimensão lateral, ou seja, trata-se da voz de um personagem que não vemos naquele momento, mas que está na cena, que já conhecemos ou que acompanhamos anteriormente participando da trama, mas que nesse momento preciso a câmera não mostra. Segundo Doane, "o uso tradicional da voz off constitui uma negação do enquadramento como limite e uma afirmação da unidade e homogeneidade do espaço representado." (1983, p.462). O termo voz over, por sua vez, é uma voz descorporificada, apresentada como fora da diegese. "Precisamente por não ser escrava de um corpo é que esta voz é capaz de interpretar a imagem, produzindo a sua verdade. Descorporificada, carente de qualquer especificação no tempo ou no espaço, a voz over está, como mostra Bonitzer, além da crítica - ela censura as perguntas 'Quem está falando?', 'Onde?', 'Em que hora?' e 'Para quem?'” (Doane, 1983: 467).

Trabalhando, sobretudo, com exemplos do cinema narrativo, o terceiro ponto abordado por Doane em seu texto diz respeito ao prazer da audição. Com uma abordagem psicanalítica em relação ao som, entendendo este como efeito determinante para o realismo no cinema, cuidadosamente planejado em 
A voz como estratégia narrativa no cinema experimental: sintonias entre a teoria feminista do cinema e as vanguardas artísticas

termos de técnicas narrativas e em termos de tecnologia de captação e de reprodução, neste domínio cinematográfico em especial, o som tem a função de sustentar o prazer narcísico derivado na imagem.

Entretanto, no documentário, a voz over passou a representar uma autoridade e uma agressividade que já não podem ser mantidas - assim, como diz Bonitzer, a proliferação de novos documentários que rejeitam o absolutismo da voz over e dizem estabelecer um sistema democrático 'permitindo ao assunto falar por si mesmo'. E mais, o que este tipo de filme realmente promove é a ilusão de que a realidade fala, ao contrário de ser falada, e que o filme não é um discurso construído. Efetuando uma 'impressão de conhecimento', um conhecimento que é dado e não produzido, o filme oculta seu próprio trabalho e coloca a si mesmo como uma voz sem sujeito. A voz é ainda mais poderosa em silêncio. A solução então não é banir a voz, mas construir outras ${ }^{10}$ políticas. (Doane, 1983: 471).

Encontrar na utilização da voz no documentário outras políticas nos interessa sobremaneira. Retornaremos a esse ponto mais adiante neste artigo quando passarmos a apresentar algumas estratégias relacionadas ao som nos filmes de Trinh T. Minh-ha, especialmente as estratégias dedicadas à locução e ao uso da voz.

Retornando aos pontos apresentados por Doane concernentes ao uso da voz no cinema, o último deles diz respeito ao que ela denominou de a política da voz. Novamente dedicando atenção principalmente ao cinema narrativo, a autora identifica que a mise-en-scène clássica trabalha para perpetuar a unidade entre imagem e som. Utiliza-se de efeitos homogeneizantes como modo de garantir a noção de realismo, de continuidade e de transparência necessários para a identificação da audiência, como forma de apagar os traços que permitem a percepção do aparato cinematográfico, estendendo o som para disfarçar o corte entre os planos, por exemplo. No caso dos documentários, essas estratégias estão expressas na opção recorrente de utilizar apenas uma voz na locução em voz over, sendo esta, geralmente, uma voz masculina. A famosa "voz de Deus".

Em outro texto, intitulado "Ideology and the practice of sound editing and mixing", publicado em 1980, Mary Ann Doane trata das questões ideológicas do aparato cinematográfico relativas à edição e à mixagem do som no cinema de modo mais amplo e não apenas em relação ao uso da voz. Nesse trabalho ela reforça os argumentos sobre o uso normativo do som no cinema hegemônico de ficção, mas chama a atenção para uma questão problemática que pode emergir na relação do som com a imagem.

10. Ênfase do original. 
Enquanto o som é introduzido, em parte, para apoiar essa ideologia, ele também arrisca uma crise ideológica em potencial. O risco reside na exposição da contradição implícita na polarização ideológica de conhecimento. Devido ao fato de som e imagem serem usados como fiadores de dois modos de conhecimento radicalmente diferentes (emoção e intelecção), sua combinação acarreta a possibilidade de expor uma fissura ideológica - uma fissura que aponta para a irreconciabilidade de duas verdades da ideologia burguesa. As práticas de edição de som e mixagem são projetadas para mascarar essa contradição através da especificação de relações permitidas entre som e imagem ${ }^{11}$. (Doane, 1980: 50).

Essas considerações de Doane reforçam que a investigação acadêmica sobre o aparato cinematográfico deve lançar luzes sobre a estética do cinema, sobretudo em um meio social interessado em subverter as convenções amplamente utilizadas no cinema narrativo hegemônico, como é o caso do campo do cinema experimental. Conhecer a forma cinematográfica e sua técnica é essencial para explorar suas possibilidades expressivas de modo pleno, expandindo o potencial do cinema como meio de expressão, e, sobretudo, para nos fazer ver como a investigação não deve estar centrada apenas nos aspectos da imagem, tão amplamente estudada no âmbito da teoria do cinema, mas deve incluir o som como objeto de escrutínio.

Nas questões dedicadas às análises da voz no cinema e em sintonia com as proposições de Doane, temos também o trabalho de Kaja Silverman, especialmente os argumentos apresentados em seu texto Dis-embodying the female voice, publicado pela primeira vez em 1981. Nesse texto, assim como Doane, a autora se debruça prioritariamente sobre o cinema narrativo, para problematizar as questões relacionadas à voz no cinema e também parte da identificação da sincronização como um elemento unificador da linguagem cinematográfica. Segundo suas palavras,

A sincronização funciona como um imperativo virtual no cinema de ficção. Embora à voz masculina seja ocasionalmente permitido transcender esse imperativo completamente, e à voz feminina seja de tempos em tempos permitida uma pausa qualificada do seu rigor, ela organiza toda a relação som/imagem. Ela é a norma em relação à qual esses relacionamentos aderem ou se afastam. $^{12}$ (Silverman, 1984: 132).

11. No original: While sound is introduced, in part, to buttress this ideology, it also risks a potential ideological crisis. The risk lies in the exposure of the contradiction implicit in the ideological polarization of knowledge. Because sound and image are used as guarantors of two radically different modes of knowing (emotion and intellection), their combination entails the possibility of exposing an ideological fissure - a fissure which points to the irreconcilability of two truths of bourgeois ideology. Practices of sound editing and mixing are designed to mask this contradiction through the specification of allowable relationships between sound and image.

12. No original: Synchronization functions as a virtual imperative within fiction film. Although the male voice is occasionally permitted to transcend that imperative altogether, and the female voice is from time to time allowed a qualified respite from its rigors, it organizes all 
A voz como estratégia narrativa no cinema experimental: sintonias entre a teoria feminista do cinema e as vanguardas artísticas

Seguindo os princípios da teoria feminista do cinema, Silverman identifica a normatização em relação ao cinema narrativo hegemônico como sendo orientada por uma lógica masculina, em que a opressão sexista em favor do homem como elemento central e agregador da narrativa atua como força onisciente na organização dos elementos do filme. A diferenciação entre os gêneros coloca sempre em desvantagem as estratégias associadas ao feminino. Para a autora, os mecanismos de exclusão são muito mais complexos do que aqueles que negam o acesso das mulheres a uma visão autorizada, e requerem formulação cuidadosa para desvendar sua articulação. Em sua exposição ela enfatiza que o sujeito masculino assume posições de autoridade dentro e fora do filme e o sujeito feminino, ao contrário, tem sistematicamente negadas tais possibilidades, sendo excluído de qualquer autoridade discursiva.

Após desenvolver sua exposição centrando a argumentação em exemplos que miram no uso da voz no cinema narrativo, diferenciando as possibilidades narrativas geralmente cedidas ao masculino e ao feminino nas estratégias utilizadas por tais filmes, Silverman volta-se para o cinema de vanguarda para amparar sua busca por alternativas estéticas em relação a esse padrão hegemônico normativo, tal como vimos anteriormente nos argumentos de Mulvey (1989) e Doane (1980). Nas palavras da autora: "é na prática da vanguarda feminista, entretanto, que a voz feminina tem sido mais exaustivamente interrogada e utilizada de modo mais inovador. ${ }^{13}$ " (Silverman, 1984: 137).

A argumentação de Silverman desenvolve-se no sentido de apontar como a desvinculação entre corpo e voz no cinema, especialmente no caso do corpo e da voz feminina, provoca rupturas nos modelos hegemônicos de normatização nas relações entre som e imagem, de modo a provocar novas percepções acerca da representação da realidade e do próprio dispositivo cinematográfico, elaborando formas narrativas mais complexas, desafiadoras e intrigantes para o espectador. Para exemplificar seus pontos ela se baseia em alguns exemplos de documentários associados a práticas mais experimentais, especialmente os filmes News from home, de Chantal Akerman (1977) e Journeys from Berlin/71, de Yvonne Rainer (1980).

Para Silverman, o filme de Rainer é um caso notável de utilização de estratégias de tratamento da voz e, em especial, das estratégias de sincronização ou disjunção do corpo e da voz femininos no cinema. Para ela, "essas questões são tratadas de modo muito mais profundo neste que é inquestionavelmente o

sound/image relationships. It is the norm to which those relationships either adhere, or from which they deviate.

13. No original: It is in feminist avant-garde practice, though, that the female voice has been most exhaustively interrogated and most innovatively deployed. 
mais memorável uso de vozes femininas no âmbito das vanguardas feministas, se não em todo o cinema experimental. ${ }^{14 "}$ (Silverman, 1984: 143).

Yvonne Rainer é uma artista norte-americana com produção diversificada em campos distintos. Oriunda do campo da dança e do teatro, Rainer também tem atuação marcada por uma jornada interdisciplinar tanto intelectual quanto artística e uma experiência que desloca questões de um campo a outro, subvertendo os limites e as fronteiras entre disciplinas e práticas expressivas. Além disso, seu percurso criativo revela um diálogo profícuo entre a teoria e a produção artística. Seus filmes foram objeto de interesse da teoria feminista do cinema e ajudaram a moldar seus argumentos em um diálogo de mão dupla que se estabeleceu entre a artista, que, informada pela teoria, incorporou a reflexão sobre as políticas da representação em suas obras. No mundo acadêmico, suas proposições conceituais e a grande variedade da sua expressão artística sugerem modos instigantes de se repensar o empreendimento teórico.

Yvonne Rainer é uma incansável teórica, no sentido que os termos da reflexão podem mudar, mas o ato da reflexão está sempre lá. Seus filmes e suas palavras oferecem a reflexão teórica como fluxo permanente, sempre mudando. Teoria nunca tem uma voz unificada; às vezes ela parece menosprezada, às vezes ela parece ser citada com grande reverência. A teoria nunca tem um pé na certeza, e, como resultado, você frequentemente encontra teoria em lugares inesperados no trabalho de Rainer. ${ }^{15}$ (Mayne, 1999: 24).

O cinema de Yvonne Rainer nos permite notar uma simultaneidade entre sua produção artística e a teoria feminista do cinema. Dito de outro modo, podemos destacar trocas positivas entre o campo teórico emergente da teoria feminista do cinema e o campo da experimentação artística engajada com novas formas de expressão.

\section{A voz e o som no cinema de Trinh T. Minh-ha}

Diante de toda essa exposição relativa à conformação da teoria feminista do cinema e ao modo como tal teoria contribuiu para problematizar o aparato cinematográfico, com especial atenção aos elementos sonoros da linguagem cinematográfica e em particular ao papel da voz no cinema, consideramos que a produção fílmica de Trinh T. Minh-ha tem aspectos muito originais a oferecer

14. No original: These issues are treated at much greater length in what is unquestionably the most remarkable deployment of female voices within the feminist avant-garde, if not within the whole of experimental cinema.

15. No original: Yvonne Rainer is an unrelenting theorist, in the sense that the terms of reflection may change, but the act of reflection is always there. Her films and her words offer theoretical reflection as always in flux, always changing. Theory never has a unified voice; sometimes it seems to be mocked, sometimes it seems to be cited with great reverence. Theory never has a sure footing, and as a result you often find theory in unexpected places in Rainer's work. 
A voz como estratégia narrativa no cinema experimental: sintonias entre a teoria feminista do cinema e as vanguardas artísticas

para que possamos investigar o uso do som e, notadamente, da locução, no campo do documentário moderno e de fatura experimental.

É importante relembrar aqui que a formação inicial da cineasta foi na área musical. Ela possui diploma pelo National Conservatory of Music \& Theater, de Saigon (1969), bacharelado em literatura e música francesa, na Wilmington College (1972), estudos de etnomusicologia, na Université de Paris IV-Sorbonne (1974), Master of Arts em literatura francesa e etnomusicologia, pela University of Illinois, Urbana-Champaign (1973) e Master of Music (composição), pela University of Illinois, Urbana-Champaign (1976).

Dessa sua origem na atuação musical Minh-ha trouxe para sua produção fílmica a noção determinante de ritmo, fundamental na organização dos elementos expressivos do seu cinema. Entretanto, não é sobre essa questão que nos deteremos aqui, mas sobre estratégias de utilização de certos elementos em seus filmes, especificamente o som, o silêncio e o uso da voz.

\section{O som e o silêncio}

Nos filmes dirigidos por Trinh T. Minh-ha encontramos diferentes estratégias de uso da música, dos ruídos e do silêncio. No primeiro caso, temos a música incidental, tocada por músicos e instrumentistas em estúdio e adicionada na montagem, e também os casos da música tocada ao vivo diretamente na cena, como parte da diegese do filme. Em relação aos ruídos e sons captados em som direto durante o trabalho de campo, estes são frequentemente utilizados como recursos sonoros não sincrônicos de modo a desnaturalizar a associação com a imagem e adquirir outras funções, musicais e rítmicas. Há ainda o uso do silêncio como recurso narrativo.

Seus filmes Reassemblage (1982) e Naked Spaces (1985) utilizam de modo exemplar uma série de estratégias sonoras que são muitas vezes destacadas como características singulares da sua expressividade artística. Um elemento essencial desses trabalhos em particular é o caráter disjuntivo entre som e imagem. Esses filmes foram captados em película $16 \mathrm{~mm}$, com som registrado em um gravador Nagra e filmados em áreas rurais de países da África Ocidental. Entretanto, apesar da possibilidade tecnológica do registro sincrônico do som e da imagem já estar disponível no momento de produção dos filmes, neles não há uma única passagem em que imagem e som estão em sincronia. No caso de Reassemblage, os créditos em tela mostram apenas a menção um filme de Trinh T. Minh-ha, sendo que no roteiro do filme publicado posteriormente temos a indicação de que Minh-ha produziu (juntamente com Jean-Paul Bourdier), dirigiu, fotografou, escreveu e editou o filme. Baseados nessas informações, podemos supor que ela própria foi responsável pela fotografia e pelo registro 
dos sons, de modo que não poderia, com o equipamento utilizado, registrar simultaneamente ambos. Em diversas entrevistas ${ }^{16}$ Minh-ha já declarou que teve pouca experiência prévia com cinema antes de emigrar para os Estados Unidos nos anos 1970 e que a realização de Reassemblage foi marcada por um processo de aprendizado em termos de filmagem.

No caso de Naked Spaces, por sua vez, em uma primeira tela os créditos iniciais apresentam as informações de que o filme foi fotografado, escrito e teve a música gravada por Minh-ha. A referência à direção aparece marcada por um X, como que a anular este quesito. No roteiro publicado de Naked Spaces, porém, não há menção ao registro das músicas. Em uma segunda tela com créditos temos a informação de que Trinh T. Minh-ha montou o filme e que Jean-Paul Bourdier foi assistente.

O uso criativo e original da banda sonora acabou tornando-se uma das forças estéticas dos filmes. O caráter disjuntivo da montagem de Reassemblage e de Naked Spaces nos remete diretamente ao princípio da continuidade visual, da transparência e da identificação, que são aspectos centrais para o cinema narrativo, mas que são também buscados pelo cinema de cunho etnográfico convencional, por exemplo, seara com a qual estes filmes da diretora dialogam claramente. Com este princípio de articulação entre o som e a imagem, o filme desnaturaliza a representação dos corpos, do espaço e da ação que registra no Senegal, chamando a atenção para a política da representação e não para o tema. Ao assumir a disjunção como princípio narrativo radical, Reassemblage posiciona-se de modo a questionar as presunções dos modelos convencionais de cinema, especialmente dos modelos clássicos de documentário. Seguindo o pensamento de Mulvey (1989), trata-se de um exemplo contundente de que um cinema de vanguarda estética e política só pode existir enquanto contraponto ao modelo hegemônico.

Nos outros filmes da cineasta o caráter disjuntivo arrefece e a montagem ganha um caráter mais paratático - onde as imagens e cenas são organizadas sequencialmente, porém, sem guardar conjunção coordenativa entre si - articulando diversos elementos heterogêneos em uma exploração ensaística dos temas e das formas, onde não há compromisso com a linearidade, mas a justaposição de episódios que se sucedem sem se vincular a um ordenamento causal, sem explicação ou hierarquia claramente definidas. Os filmes Surname Viet Given Name Nam (1989), The Fourth Dimension (2001) e Forgetting Vietnam (2015) incluem letreiros eletrônicos sobrepostos às imagens. Imagens de arquivo (fotografias e filmagens) aparecem em Surname Viet Given Name Nam

16. Para entrevistas mais focadas nos três primeiros filmes da diretora ver Framer Framed (1992) 
A voz como estratégia narrativa no cinema experimental: sintonias entre a teoria feminista do cinema e as vanguardas artísticas

e Forgetting Vietnam. Diferentes texturas de imagem são adotadas em Shoot for the Contents e Forgetting Vietnam. O uso de música pré-gravada aparece em The Fourth Dimension (2001) e Night Passage (2004)

O silêncio é um elemento narrativo importante em Reassemblage e em $\mathrm{Na}$ ked Spaces. Quando nos referimos a silêncio estamos falando da ausência total de som realmente e não apenas de um nível baixo de registro sonoro ou coisa que o valha. Em certas passagens desses filmes, Minh-ha retira o som completamente, deixando a cena silenciosa, de modo que esse silêncio se torna ensurdecedor. Dito de outro modo, utilizando uma metáfora mais comum e associada ao campo da imagem, o uso do silêncio nesses filmes torna o trabalho com o som visível. Para Mary Ann Doane (1984) a invisibilidade do trabalho com o som é a medida da força da banda sonora do filme. Evidentemente, nos filmes aqui em questão, podemos dizer o contrário. Como forma de expor o aparato cinematográfico, causando sensação de estranhamento e desnaturalizando a identificação com o tema, os silêncios assumem um caráter ativo e marcante, contribuindo para a elaboração de uma narrativa em que imagem e som expressam dimensões sensíveis que desestabilizam as expectativas típicas das narrativas convencionais, onde comumente há a manutenção de oposições ideológicas entre o inteligível e o sensível, o intelecto e a emoção, o fato e o valor, a razão e a intuição. Nos casos aqui destacados, a evidenciação do trabalho com o som é a medida da força da estética do filme.

Passando para a dimensão do som, vamos nos dedicar ao tema a partir de dois aspectos: os sons gravados em campo e utilizados de modo não sincrônico com a imagem na montagem, e a utilização de músicas.

O primeiro caso, dos sons não-sincrônicos, está mais fortemente presente nos dois filmes iniciais da cineasta, mas em menor escala também aparece nos demais. Nos casos dos filmes realizados na África, os sons registrados em campo são utilizados de modo a compor uma sonoridade rítmica, afastando-se de uma função que poderia ser ilustrativa ou de contextualização. Temos sons de trabalhos manuais, como o pilar do alimento pelas mulheres, sons de insetos, de falas, cantos de trabalho e cânticos rituais. Entretanto, nenhum deles se oferece como suporte para a imagem, sendo trabalhados de forma autônoma. Mesmo quando os sons são relativos à imagem, como no caso das mulheres que estão trabalhando no pilão, o som não é sincrônico e o que prevalece é o ritmo da montagem, da articulação entre imagem e som, e não a ilustração ou a descrição, seja da imagem em relação ao som ou vice-versa. Nesses casos, os sons são trabalhados como na música concreta, ou seja, uma composição musical que se constrói na montagem, incorporando elementos a princípio estranhos ao universo musical, como ruídos e sons naturais registrados anterior- 
mente, para deles extrair musicalidade. Ao invés da composição musical nos moldes convencionais, onde estão envolvidos instrumentos e músicos, aqui a sonoridade surge da montagem desses ruídos na etapa de pós-produção.

Em relação ao segundo caso, a utilização de músicas, temos duas situações: a música incidental sobreposta à imagem, e a música registrada dentro da diegese no ato da filmagem, conforme apontamos anteriormente. A música incidental aparece nos filmes de Trinh T. Minh-ha em uma multiplicidade de usos. Por exemplo, a partir de arquivos, contribuindo para tecer uma narrativa que revisita a dimensão histórica a partir de experiências individuais, como é o caso dos filmes Surname Viet Given Name Nam e Forgetting Vietnam, que utilizam poemas ou cânticos tradicionais, ou então a partir de registros pela câmera de rituais encenados, como é o caso nos filmes Shoot for the contents e The Fourth Dimension. Aqui acompanhamos espetáculos performáticos e musicais e cerimônias que revisitam tradições culturais e folclóricas cujos sons passam do diegético para o extradiegético na articulação da montagem.

O filme Night passage é um caso interessante de experimentação com a música em relação à narrativa. As personagens Kyra, Nabi e Shin vão percorrendo as salas e espaços na viagem que empreendem pela "passagem noturna". Nesses locais elas encontram outros personagens, que lidam com dimensões diferentes da performance. Temos situações dedicadas à palavra, aos movimentos, às luzes e aos sons e que inserem as personagens principais em experiências dentro do filme. Experiências com a tecnologia, com expressões artísticas, com diferentes sensações e energias. A maneira de realizar este trabalho conjugou experiências com a câmera, resultado da encenação para o filme e experiências na cena, na diegese, onde as personagens se depararam com performances sendo executadas diretamente no desenrolar da cena. Esta situação é particularmente interessante no caso da música. Em diversas cenas há música sendo interpretada em tempo real, no próprio transcorrer do plano e a interpretação desta está em sintonia com o desenvolvimento da ação. A música incidental não é apenas inserida em um trabalho de edição posterior, com ajustes controlados de duração e transições, mas é executada em sintonia com o trabalho dos atores e da câmera, devendo lidar com as dimensões de duração e transição dentro da execução do plano. Uma situação de filmagem em direto que remete ao documentário, executada em uma encenação ficcional.

Logo no início do filme, quando Kyra sai do seu local de trabalho, temos a primeira situação onde a música está sendo interpretada diretamente na cena, como parte da diegese. Kyra sai de bicicleta do galpão onde trabalha. $\mathrm{O}$ som da flauta começa. Ela cruza com um homem e uma mulher, que estão por ali em frente ao galpão, sentados. A música da flauta tocando uma melodia. 
A voz como estratégia narrativa no cinema experimental: sintonias entre a teoria feminista do cinema e as vanguardas artísticas

O homem chama Kyra, que retorna ao encontro deles. A câmera acompanha Kyra em uma panorâmica horizontal e enquadra os três no plano: Kyra, o homem e a flautista. Kyra e o homem começam a conversar sobre problemas, sonhos e os caminhos da vida. A flautista toca seu instrumento pontuando o diálogo entre os atores. O plano permanece o mesmo, sem decupagem. Os três em cena simultaneamente. Após a conversa, Kyra levanta-se e caminha para a bicicleta, a câmera a acompanha em uma panorâmica horizontal, deixando o homem e a flautista fora do quadro. A flautista retoma a melodia que preenche a cena da saída de Kyra. Em outra cena mais adiante, já dentro do trem que faz a "passagem noturna", Kyra, Nabi e Shin encontram-se com dois contadores de história em um dos vagões. Um deles conta histórias cantando a capella. Mais adiante as três personagens estão em outro espaço, um ambiente aberto, brincando com cores e formas desenhadas no chão, quando seguem uma linha colorida fazendo a passagem para outro espaço maior, onde um baterista está tocando uma bateria eletrônica, sendo acompanhado por um percussionista. Algumas pessoas sentadas ao redor assistindo. Novamente sem decupagem, apenas um plano de câmera. Neste caso o plano começa fechado no baterista e vai se abrindo em zoom out, incluindo todos em cena. Kyra brinca com uma bola metálica dançando ao som da música. Nabi passeia de patins, em movimentos circulares ao redor. Shin brinca com o projetor de luz. Lentamente as personagens vão saindo do quadro, no que são acompanhados pela câmera em uma panorâmica lateral, até chegarem a uma figura humana desenhada no chão com pontos luminosos. O som da bateria e da percussão permanece. A última cena que apresenta música inserida na diegese acontece em uma sala de jantar, local em que as personagens confraternizam com algumas pessoas à mesa. Ao chegar à sala, as personagens recebem captadores de som que são colocados no rosto. Ao fundo temos um grupo de música eletrônica experimental, com uma série de equipamentos eletrônicos ligados. Os músicos vão compondo em interação com a cena, incorporando os sons gerados pelos dispositivos presos no rosto de cada ator. Movimentos físicos se transformam em sons manipulados eletronicamente dentro da própria diegese do filme.

Em relação à utilização de músicas pré-gravadas, Trinh T. Minh-ha trabalhou com o grupo de música instrumental experimental The Construction of Ruins nos filmes A Tale of Love, The Fourth Dimension e Night Passage. O trabalho do grupo resulta de uma improvisação bastante livre, utilizando instrumentos adaptados, como o piano 'preparado ${ }^{17}$, , nos moldes dos instrumentos de músicos de vanguarda como John Cage. O trabalho com este grupo

17. Objetos estranhos ao piano são inseridos nas cordas do instrumento, como parafusos e moedas, a fim de obter novas e inusitadas sonoridades. 
é baseado na improvisação e busca trazer para o campo sonoro a mesma liberdade e inventividade almejada no campo visual. O grupo trabalha de modo bastante experimental, sem seguir estruturas musicais definidas, como seria esperado de uma música no sentido convencional. Como um grupo de vanguarda tampouco vê limites entre o que é ruído e o que é música, abusando das sonoridades dissonantes. Para R. Murray Schaffer, um importante teórico no campo musical,

Às vezes, a dissonância é chamada de ruído; e para os ouvidos tímidos até pode ser isso. Porém, consonância e dissonância são termos relativos e subjetivos. Uma dissonância para uma época, geração e/ou indivíduo pode ser uma consonância para outra época, geração e/ou indivíduo. A dissonância mais antiga na história da música foi a Terça-Maior (dó-mi). A última consonância na história da música foi a Terça-Maior (dó-mi). (1991: 69).

Podemos notar que no cinema de Trinh T. Minh-ha o aspecto musical ressoa a utilização de estratégias desafiadoras como aquelas utilizadas no âmbito da imagem, de modo a contribuir para propor uma experiência fílmica que pretende encontrar caminhos novos para representar uma visão particular de mundo.

\section{A voz}

A cineasta explorou uma multiplicidade de possibilidades no uso da locução em voz over, demonstrando, como o modelo convencional ou clássico de documentário é limitador em sua estrutura narrativa excessivamente normatizada. A locução evidencia a importância da palavra falada para Trinh $\mathrm{T}$. Minh-ha (ao lado da palavra escrita dos letreiros e da palavra escrita nos livros) e permite a cineasta explorar dimensões retóricas, poéticas, líricas e pessoais que subvertem os modelos narrativos recorrentes no cinema. A voz no cinema de Trinh T. Minh-ha é elemento fundamental para o desenvolvimento de seu caráter ensaístico, principal linha de força de seu cinema. É no espaço da locução que a cineasta exerce com plenitude seu discurso.

Vamos recorrer a Mary Ann Doane, buscando seus argumentos em favor daquilo que chamou de a política da voz, no texto "A voz no cinema: a articulação de corpo e espaço". Para a autora, o documentário clássico trabalha para confinar a voz over em uma única voz, que ao lado da sincronização entre imagem e som, atua como forma de buscar obter um efeito homogeneizante, de unidade. Como já vimos em diversas passagens, o que interessa para Trinh T. Minh-ha é trabalhar na multiplicidade, buscar a diferença na multiplicidade. Esta busca pode ser traduzida em seus diferentes filmes nas estratégias de locução adotadas, por exemplo, no uso de duas vozes distintas, como em Shoot 
for the contents, ou mesmo três vozes distintas, como em Naked Spaces. "Isto implica não apenas aumentar o número de vozes, mas radicalmente mudar o relacionamento delas para com a imagem, efetuando uma disjunção entre som e significado, fazendo prevalecer aquilo que Barthes define como o'grão' da voz sobre e contra sua expressividade ou poder de representação." (Doane, 1983: 472-473).

Em último lugar, devemos ressaltar que nos filmes de Trinh T. Minh-ha a locução, mesmo quando não é feita por ela própria, é carregada de sotaque. Nos filmes da cineasta praticamente todas as locuções em voz over são em inglês. Com excessão das duas entrevistas de Shoot for the Contents e de alguns outros personagens aqui e ali, quase sempre são mulheres que falam. Em praticamente todos esses casos o inglês não é a língua materna de quem fala e as vozes são frágeis e delicadas. Desse modo, as vozes carregam dois elementos - sotaque e fragilidade - que perturbam as normas daquilo que o modelo convencional normatizou como sendo esperado do recurso da locução em voz over: a locução masculina, de voz grave e assertiva. Para Barthes (1977), a voz não é pessoal, não é original, porém ao mesmo tempo é individual: ela tem um corpo que ouvimos, que não tem identidade civil, não tem personalidade, mas tem mesmo assim um corpo separado. Acima de tudo, a voz carrega diretamente o simbólico, acima do inteligível, o expressivo.

Pela voz há a afirmação da diferença de seu cinema, protagonizado por mulheres, não raro em situações de deslocamento, de diáspora, que refletem a experiência intercultural a partir dos intervalos e dos cruzamentos entre culturas, lugares e instâncias de poder.

\section{Referências bibliográficas}

Barthes, R. (1977). The grain of voice. In R. Barthes, Image-music-text (pp. 179-189). Fontana Press.

Deren, M. (2012). Cinema: o uso criativo da realidade. Devires, 9 (1): 128149.

Doane, M. A. (1984). The 'woman's film': possession and address. In M. A. Doane et al., Re-vision: essays in feminist film criticism (pp. 67-82). American Film Institute monograph series v.3.

Doane, M. A. (1983). A voz no cinema: a articulação de corpo e espaço. In I. Xavier, A experiência do cinema (pp. 457-475). Rio de Janeiro: Edições Graal: Embrafilme.

Doane, M. A. (1981). Woman's stake: filming the female body. October, 17: 22-36. 
Doane, M. A. (1980). Ideology and practice of sound editing and mixing. In T. Lauretis \& S. Heath, The cinematic apparatus (pp. 47-56). Macmillan press.

Johnston, C. (1976). Women's Cinema as Counter cinema. In B. Nichols (ed.), Movies and methods (pp. 208-221). University of California Press.

Mayne, J. (1999). Theory speak(s). In Y. Rainer, A woman who: essays, interviews, scripts (pp. 18-24). JHU Press.

Mulvey, L. (1989). Film, feminism and the avant-garde. In L. Mulvey, Visual and other pleasures (pp. 111-126). Palgrave.

Mulvey, L. (1983). Prazer visual e cinema narrativo. In I. Xavier, A experiência do cinema (pp. 437-453). Rio de Janeiro: Edições Graal: Embrafilme.

Schafer, M. (1991). O ouvido pensante. São Paulo: Editora da Unesp.

Silverman, K. (1984). Dis-embodying the female voice. In M. A. Doane et al, Re-vision : essays in feminist film criticism (pp. 131-149). American Film Institute Monograph Series, v.3. AFI.

Trinh T. M. (1992). Framer framed. Nova York: Routledge. 